\title{
PENINGKATAN PERTUMBUHAN DAN HASIL BAWANG MERAH (Allium ascalonicum L) DENGAN APLIKASI PERBEDAAN KONSENTRASI BIO SLURRY DAN PEMOTONGAN UMBI BIBIT
}

\author{
Mustofa Bin Wagiman'), Pramono Hadi ${ }^{1)}$ Tri Rahayu ${ }^{1)}$ \\ ${ }^{1)}$ Prodi Agroteknologi Fakultas Pertanian Universitas Islam Batik Surakarta \\ Korespondensi: ulyaraihan5@gmail.com \\ ammarmustofa30@gmail.com
}

\begin{abstract}
ABSTRAK
Tujuan penelitian mengetahui pengaruh konsentrasi bio slurry dan pemotongan umbi bibit terhadap pertumbuhan dan hasil tanaman bawang merah. Menggunakan metode faktorial Rancangan Acak Kelompok Lengkap (RAKL), terdiri atas dua faktor yaitu konsentrasi bio slurry dan pemotongan umbi, adapun kedua faktor perlakuan dengan 12 kombinasi perlakuan, masing-masing perlakuan diulang (3) kali. Perlakuan pertama, perlakuan konsentrasi bio slurry $(\mathrm{S})$ yang terdiri atas 4 taraf yaitu $\left(\mathrm{S}_{1}\right.$ : konsentrasi bio slurry $0 \mathrm{ml} / 1, \mathrm{~S}_{2}$ : konsentrasi bio slurry $50 \mathrm{ml} / 1, \mathrm{~S}_{3}$ : konsentrasi bio slurry $100 \mathrm{ml} / \mathrm{l}, \mathrm{S}_{4}$ : konsentrasi bio slurry $150 \mathrm{ml} / \mathrm{l}$ ). Perlakuan kedua, perlakuan dengan pemotongan umbi bibit $(\mathrm{P})$ yang terdiri atas tiga taraf $\left(\mathrm{P}_{1}\right.$ : Pemotongan umbi bibit $1 / 4$ bagian, $\mathrm{P}_{2}$ : Pemotongan umbi bibit $1 / 3$ bagian, $\mathrm{P}_{3}$ : Pemotongan umbi bibit $1 / 2$ bagian). Hasil penelitian menunjukkan bahwa perlakuan dengan konsentrasi bio slurry (S) berpengaruh tidak nyata terhadap semua pengamatan. Perlakuan dengan pemotongan umbi bibit $(\mathrm{P})$ berpengaruh sangat nyata terhadap tinggi tanaman, berat umbi segar per tanaman, berat umbi segar per petak dan berpengaruh nyata terhadap jumlah umbi segar per tanaman, namun tidak berpengaruh nyata terhadap jumlah umbi per petak dan berat berangkasan segar. Kombinasi antara konsentasi bio slurry dan pemotongan umbi bibit (SxP) tidak berpengaruh nyata terhadap semua pengamatan namun hasil berat umbi segar per petak tertinggi diperoleh pada perlakuan konsentrasi bio slurry $50 \mathrm{ml} / \mathrm{l}$ dengan pemotongan umbi bibit $1 / 3$ bagian dan hasil $800,00 \mathrm{~g}$, sedangkan berat umbi per petak terendah diperoleh pada perlakuan konsentrasi bio slurry $0 \mathrm{ml} / \mathrm{l}$ dan pemotongan umbi bibit $1 / 2$ bagian dengan hasil $433,33 \mathrm{~g}$.
\end{abstract}

Kata Kunci: pemotongan umbi bibit, konsentrasi bio slurry, bawang merah.

\section{ABSTRACT}

The research objective was to determine the effect of the concentration of bio slurry and cutting tubers on the growth and yield of shallot plants. Using the factorial method Completely Randomized Block Design (CRBD), consisting of two factors, namely the concentration of bio slurry and tuber cutting, while the two treatment factors with 12 treatment combinations, each treatment was repeated (3) times. The first treatment, the concentration of bio slurry (S) which consists of 4 levels, namely (S1: bio slurry concentration $0 \mathrm{ml} / 1, \mathrm{~S} 2$ : bio slurry concentration $50 \mathrm{ml} / 1$, S3: bio slurry concentration $100 \mathrm{ml} / 1$, S4: concentration bio slurry $150 \mathrm{ml} / \mathrm{l}$ ). The second treatment was cutting the seed tubers $(\mathrm{P})$, which consisted of three levels (P1: Cutting 1/4 part of seed tubers, $\mathrm{P} 2$ : Cutting 1/3 parts of seed tubers, P3: Cutting 1/2 parts of seed tubers). The results showed that the treatment with the concentration of bio slurry (S) had no significant effect on all observations. Treatment by cutting seed tubers $(\mathrm{P})$ had a very significant effect on plant height, weight of fresh tubers per plant, weight of fresh tubers per plot and had a significant effect on the number of fresh tubers per plant, but had no significant effect on the 
number of tubers per plot and weight of fresh stems. The combination of bio slurry concentration and cutting of seed tubers $(\mathrm{SxP})$ did not significantly affect all observations but the highest yield of fresh tuber weight per plot was obtained in the $50 \mathrm{ml} / 1$ bio slurry concentration treatment by cutting seed tubers $1 / 3$ part and yielding $800.00 \mathrm{~g}$, whereas the lowest tuber weight per plot was obtained in the treatment of $0 \mathrm{ml} / 1$ bio slurry concentration and $1 / 2$ part cutting of seed tubers with a yield of $433.33 \mathrm{~g}$.

Keywords: cutting seed tubers, bio slurry concentration, shallots.

\section{PENDAHULUAN}

Salah satu komoditas hortikultura potensial adalah bawang merah (Allium ascalonicum L) karena mempunyai nilai ekonomi dan permintaan pasar yang cukup tinggi dan prospektif (Anonim, 2007). Komoditas ini menjadi komoditas strategis yang mempunyai kontribusi cukup tinggi terhadap pertumbuhan ekonomi nasional khususnya dalam upaya peningkatan pendapatan dan kesejahteraan rakyat. Menurut (Suriani, 2012), sebagai komoditas hortikultura yang banyak di konsumsi masyarakat, potensi pengembangan bawang merah masih terbuka lebar bukan hanya untuk kebutuhan dalam negeri tetapi juga kebutuhan luar negeri.

Salah satu cara untuk meningkatkan produksi bawang merah adalah dengan perbaikan teknik budidaya dan pemberian pupuk organik. Menurut Irfan (2013), pertumbuhan dan perkembangan tanaman sangat dipengaruhi oleh pemberian pupuk dan ketersediaan unsur hara di dalam tanah. Pemberian pupuk organik memiliki kelebihan yaitu ramah lingkungan, memperbaiki sifat fisik, kimia serta biologi tanah (Laude \& Hadid, 2007). Limbah cair biogas adalah salah satu dari pupuk organik yang dapat digunakan pada tanaman. Pupuk limbah cair dari proses biogas merupakan pupuk dari kotoran hewan ternak yang difermentasi. Berdasarkan analisis dalam pupuk cair bio slurry mengandung banyak unsur hara yaitu Corganik (48\%), N-total (2,9\%), C/N (15,8\%), P2O5 (0,2\%), K2O (0,3\%).

Menurut Hadisuwito (2007), bio-slurry cair memiliki manfaat yaitu dapat memperbaiki sifat-sifat tanah, menghasilkan produk pertanian yang aman dan mengandung mikroorganisme yang dapat menyuburkan tanah dan menambah nutrisi serta dapat mengendalikan penyakit pada tanah. Limbah cair biogas juga dapat mudah diserap oleh tanaman karena unsur-unsur yang terkandung didalamnya sudah terurai. Hal ini disebabkan karena pupuk limbah cair biogas mengalami dekomposisi oleh bakteri anaerob di dalam tabung penampungan (Yunus, 1991).

Selain pemupukan, untuk meningkatkan hasil bawang merah dengan perlakuan pemotongan ujung umbi bibit dengan pisau bersih kira-kira 1/3 atau 1/4 bagian dari panjang umbi, yang bertujuan agar umbi tumbuh merata, dapat merangsang tunas, mempercepat 
tumbuhnya tanaman, dapat merangsang tumbuhnya umbi samping dan dapat mendorong terbentuknya anakan (Wibowo, 2005). Selanjutnya Samadi \& Cahyono.(2005) menambahkan sebelum umbi bawang merah ditanam, pada bahagian ujung umbi dipotong sebesar $1 / 3-1 / 4$ bahagian, sesuai kondisi bibit. Tujuan pada penelitian ini adalah untuk mengetahui pengaruh konsentrasi bio slurry dan pemotongan umbi terbaik pada tanaman bawang merah.

\section{METODE PENELITIAN}

Penelitian ini telah dilaksanakan pada bulan April 2020 sampai bulan Juni 2020 di Kebun Tanaman Pangan dan Hortikultura Dukuh Kepoh Desa Tohudan, Kecamatan Colomadu, Kabupaten Karanganyar dengan ketinggian \pm 105 m dpl. Bahan-bahan yang digunakan untuk penelitian ini yaitu benih bawang merah varietas bima brebes, pupuk organik cair bio slurry, pupuk kandang kambing sebagai pupuk dasar. Penelitian ini menggunakan rancangan lingkungan dengan pola dasar Rancangan Acak Kelompok Lengkap (RAKL) dengan 3 (tiga) ulangan. Terdapat dua faktor perlakuan yang diteliti yaitu konsentrasi bio slurry (S) yang terdiri dari $\mathrm{S}_{0}$ : konsentrasi $0 \mathrm{ml} / 1, \mathrm{~S}_{1}$ : konsentrasi $50 \mathrm{ml} / 1, \mathrm{~S}_{2}$ : konsentrasi $100 \mathrm{ml} / \mathrm{l}$ dan $\mathrm{S}_{3}$ : konsentrasi $150 \mathrm{ml} / \mathrm{l}$. Perlakuan kedua adalah model pemotongan umbi bibit $(\mathrm{P})$ yang terdiri dari $\mathrm{P}_{1}$ : pemotongan $1 / 4$ bagian, $\mathrm{P}_{2}$ : pemotongan $1 / 3$ bagian dan $\mathrm{P}_{3}$ : pemotongan $1 / 2$ bagian

Proses pembuatan pupuk organik cair bio slurry yaitu dengan menampung limbah kotoran dan urin ternak dalam wadah besar dalam keadaan tertutup agar terjadi fermentasi secara anaerobik selama kurang lebih satu bulan, lalu setelah keluar dari outlet cairan di saring dengan kain, kemudian cairan didiamkan selama paling sedikit 2 minggu sebelum diaplikasikan. Pada tanaman dalam petak-petak perlakuan konsentrasi bio slurry sesuai dengan dosis perlakuan $0 \mathrm{ml} / 1,50 \mathrm{ml} / 1,100 \mathrm{ml} / 1,150 \mathrm{ml} / 1$ mulai tanaman berumur 10 hari dan diberikan dengan interval waktu 7 hari sekali sampai menjelang panen. Pengamatan yang diamati yaitu tinggi tanaman, berat umbi segar per tanaman, berat umbi segar per petak, jumlah umbi segar per tanaman, jumlah umbi segar per petak dan berat berangkasan segar.

\section{HASIL DAN PEMBAHASAN}

Pada perlakuan pemotongan menunjukkan bahwa umbi bibit (P) berpengaruh sangat nyata pada pengamatan: tinggi tanaman, berat umbi per tanaman, berat bumbi per petak dan berpengaruh nyata pada jumlah umbi per tanaman, sedangkan jumlah umbi per petak dan berat berangkasan segar tidak memberikan pengaruh yang nyata. Pada perlakuan konsentrasi bio slurry (S) serta interaksi konsentrasi bio slurry dan pemotongan umbi bibit (SxP) tidak 
memberikan pengaruh yang nyata terhadap semua pengamatan. Hasil penelitian pada (Tabel 1)

Tabel 1. Pertumbuhan dan hasil bawang merah dengan aplikasi perbedaan konsentrasi bio slurry dan pemotongan umbi bibit.

\begin{tabular}{|c|c|c|c|c|c|c|}
\hline \multirow[t]{2}{*}{ Parameter } & \multirow{2}{*}{$\begin{array}{c}\text { Pemotongan } \\
\text { (P) }\end{array}$} & \multicolumn{4}{|c|}{ Konsentrasi (S) } & \multirow[t]{2}{*}{ Rerata } \\
\hline & & S0 & S1 & S2 & S3 & \\
\hline \multirow{4}{*}{$\begin{array}{l}\text { Tinggi Tanaman } \\
(\mathrm{cm})\end{array}$} & P1 & 37,10 & 36,97 & 38,01 & 29,38 & $35,36^{\mathrm{a}}$ \\
\hline & $\mathrm{P} 2$ & 31,21 & 34,80 & 34,51 & 35,11 & $33,91^{\mathrm{b}}$ \\
\hline & $\mathrm{P} 3$ & 28,79 & 24,11 & 23,65 & 25,12 & $25,42^{\mathrm{c}}$ \\
\hline & Rerata & 32,36 & 31,96 & 32,06 & 29,87 & \\
\hline \multirow{4}{*}{$\begin{array}{l}\text { Berat Umbi Segar } \\
\text { per Tanaman }(\mathrm{g})\end{array}$} & $\mathrm{P} 1$ & 31,67 & 28,27 & 23,60 & 30,20 & $28,43^{\mathrm{b}}$ \\
\hline & $\mathrm{P} 2$ & 25,33 & 28,40 & 32,00 & 30,67 & $29,10^{\mathrm{b}}$ \\
\hline & $\mathrm{P} 3$ & 22,20 & 17,33 & 18,47 & 18,33 & $19,08^{\mathrm{a}}$ \\
\hline & Rerata & 26,40 & 24,67 & 24,69 & 26,40 & \\
\hline \multirow{4}{*}{$\begin{array}{l}\text { Berat Umbi Segar } \\
\text { per Petak }(\mathrm{g})\end{array}$} & $\mathrm{P} 1$ & 791,67 & 706,67 & 590,00 & 755,00 & $710,83^{t}$ \\
\hline & $\mathrm{P} 2$ & 633,33 & 710,00 & 800,00 & 766,67 & $727,50^{1}$ \\
\hline & $\mathrm{P} 3$ & 555,00 & 433,33 & 461,67 & 458,33 & 477,08 \\
\hline & Rerata & 660,00 & 616,67 & 617,22 & 660,00 & \\
\hline \multirow{4}{*}{$\begin{array}{l}\text { Jumlah Umbi Segar } \\
\text { per Tanaman }\end{array}$} & $\mathrm{P} 1$ & 5,60 & 5,67 & 4,80 & 5,40 & $5,37^{\mathrm{c}}$ \\
\hline & $\mathrm{P} 2$ & 5,67 & 4,47 & 4,93 & 5,20 & $5,07^{\mathrm{b}}$ \\
\hline & $\mathrm{P} 3$ & 3,87 & 4,60 & 4,67 & 4,60 & $4,43^{\mathrm{a}}$ \\
\hline & Rerata & 5,04 & 4,91 & 4,80 & 5,07 & \\
\hline \multirow{4}{*}{$\begin{array}{l}\text { Jumlah Umbi Segar } \\
\text { per Petak }\end{array}$} & $\mathrm{P} 1$ & 140,00 & 142,00 & 120,00 & 135,00 & 134,25 \\
\hline & $\mathrm{P} 2$ & 141,67 & 111,67 & 140,00 & 130,00 & 130,83 \\
\hline & $\mathrm{P} 3$ & 96,67 & 115,00 & 116,67 & 115,00 & 110,83 \\
\hline & Rerata & 126,11 & 122,89 & 125,56 & 126,67 & \\
\hline Berat Berangkasan & $\mathrm{P} 1$ & 12,66 & 15,55 & 14,78 & 13,77 & 14,19 \\
\hline \multirow[t]{3}{*}{ Segar $(g)$} & $\mathrm{P} 2$ & 13,22 & 13,92 & 14,11 & 14,00 & 13,81 \\
\hline & $\mathrm{P} 3$ & 12,78 & 13,44 & 13,66 & 13,00 & 13,22 \\
\hline & Rerata & 12,89 & 14,30 & 14,18 & 13,59 & \\
\hline
\end{tabular}

Keterangan : angka-angka yang diikuti huruf yang sama pada baris atau kolom yang sama tidak berbeda nyata pada uji DMRT 5\%

\section{Tinggi Tanaman}

Perlakuan pemotongan umbi bibit berpengaruh sangat nyata terhadap pengamatan tinggi tanaman. Pemotongan $1 / 2$ bagian umbi bibit $\left(\mathrm{P}_{3}\right)$ memberikan hasil terbaik yaitu $35,36 \mathrm{~cm}$ yang berbeda nyata dengan $\mathrm{P}_{1}$ dan $\mathrm{P}_{2}$. 


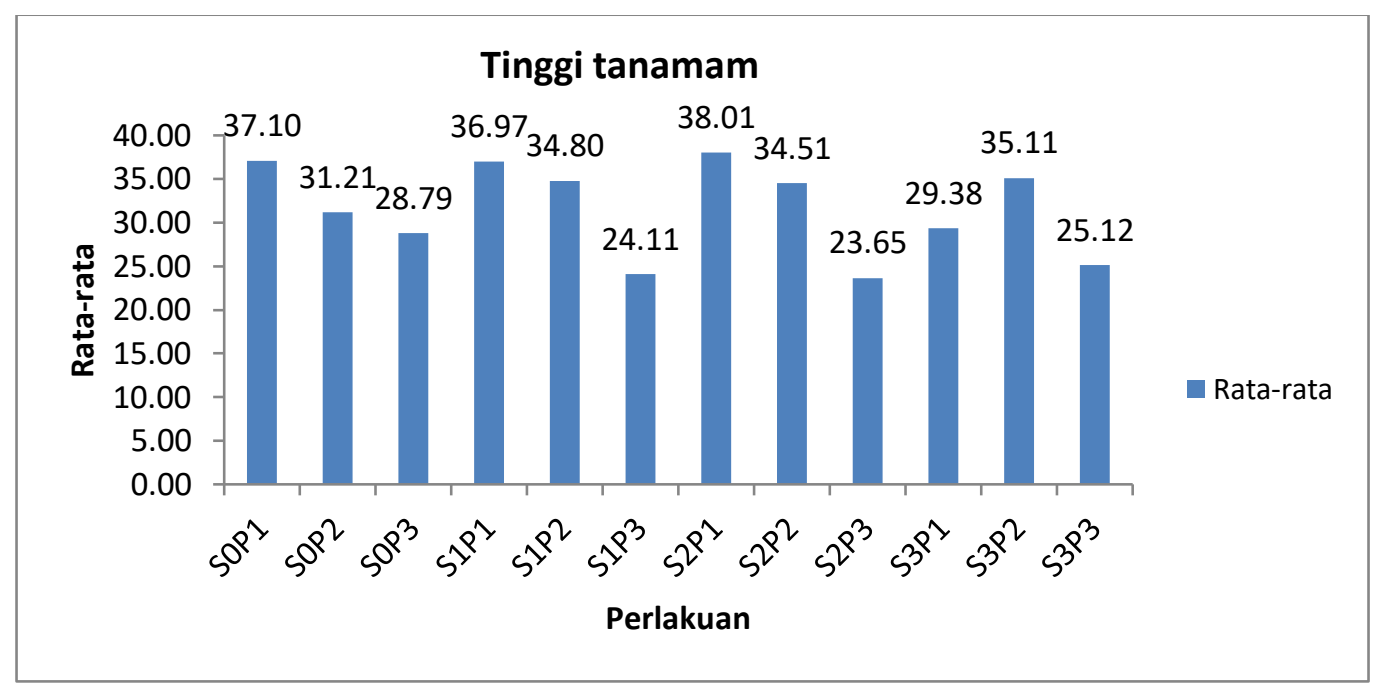

Hal ini sesuai dengan pendapat Rukmana (1995) bahwa pemotongan umbi bibit akan mempercepat daya tumbuh tanaman dan memperbanyak anakan. Tujuan pemotongan ujung umbi bibit ini adalah agar umbi dapat tumbuh merata, merangsang pertumbuhan tunas, mempercepat tumbuhnya tanaman, dan merangsang tumbuhnya anakan. sebelum umbi bibit bawang merah ditanam, sebaiknya dilakukan pemotongan umbi bibit 1/2 bagian. Hubungan dengan penelitian jika umbi bibit yang akan ditanam, dipotong terlebih dahulu ujungnya satudua hari sebelum penanaman kira-kira 1/2 dan 1/4 bagian dari panjang umbi keseluruhan maka pertumbuhan bibit merata (seragam). Hasil penelitian Mufairoh et al. (2018) menunjukkan bahwa pemberian pupuk bio-slurry berpengaruh terhadap pertumbuhan bawang merah. Perlakuan pemberian pupuk setiap minggu dengan dosis $100 \mathrm{ml}$. menunjukkan hasil yang terbaik pada setiap pengamatan tinggi tanaman.

\section{Berat Umbi Segar Per Tanaman}

Berat umbi segar per tanaman tertinggi diperoleh pada perlakuan $\mathrm{P}_{2}$ (pemotongan umbi bibit $1 / 3$ bagian) $29,10 \mathrm{~g}$, namun hasil tersebut tidak berbeda nyata terhadap perlakuan $\mathrm{P}_{1}$ tetapi berbeda nyata dengan perlakuan $\mathrm{P}_{3}$.

Hal ini dapat terjadi karena pemotongan umbi bibit 1/3 bagian tidak mengganggu bakal tunas dan tidak mengurangi cadangan makanan pada umbi bawang merah sehingga tidak menghambat proses fotosintesis dan menghasilkan bobot umbi yang cenderung lebih besar dibandingkan dengan perlakuan lainnya. Menurut Purnama (2014), bahwa tingkat pemotongan yang lebih banyak menyebabkan luka pada umbi dan luka tersebut mempengaruhi umbi pada saat pertumbuhan sehingga menurunkan hasil bobot umbi. Hasil penelitian Puspa (2019). menunjukan bahwa pemberian pupuk organik kotoran sapi dengan takaran 15 ton/ha atau 
$3 \mathrm{~kg} /$ petak dengan penggunaan mulsa jerami padi menghasilakan produksi tertinggi yaitu 2,13 $\mathrm{kg} /$ petak atau setara dengan 8,52 ton/ha berat umbi segar per tanaman.

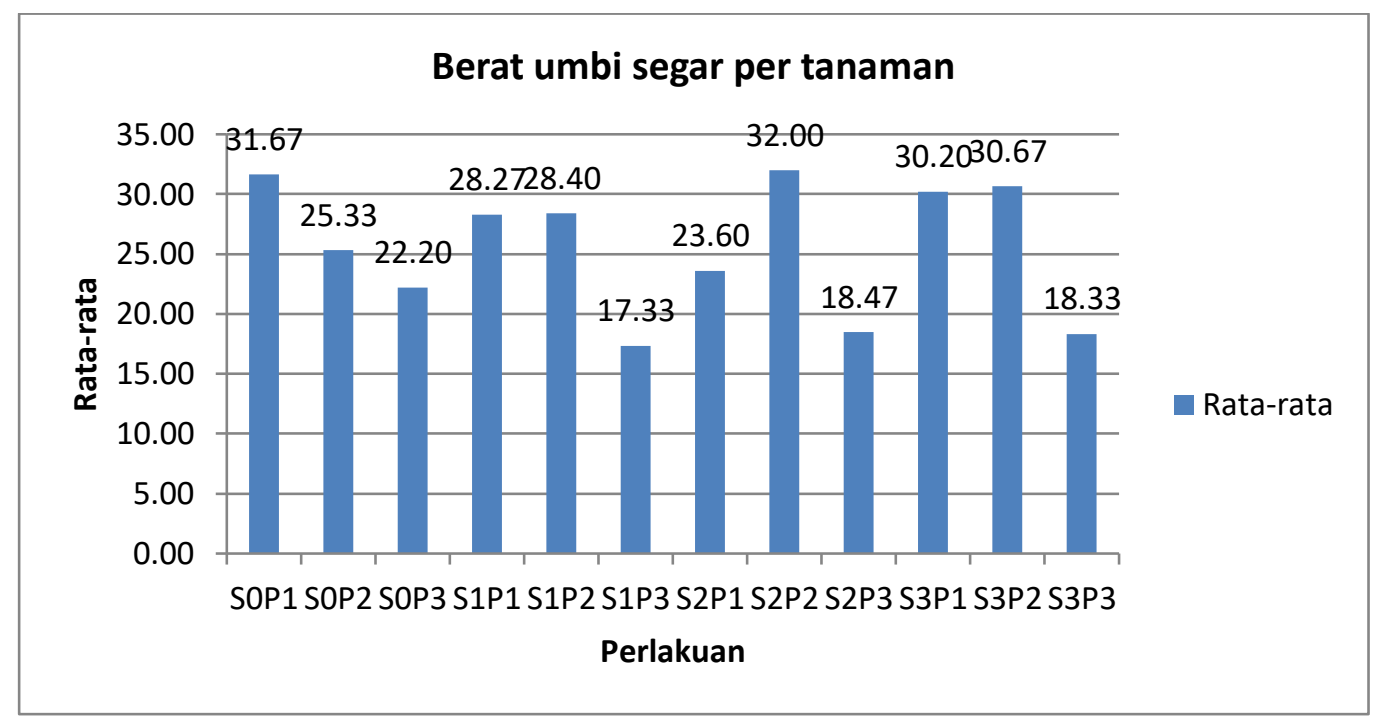

\section{Berat Umbi Segar Per Petak}

Berat umbi segar per petak tertinggi diperoleh pada perlakuan $\mathrm{P}_{2}$ (pemotongan umbi bibit $1 / 3$ bagian) $727,50 \mathrm{~g}$, namun hasil tersebut tidak berbeda nyata terhadap perlakuan $\mathrm{P}_{1}$ tetapi berbeda nyata terhadap perlakuan $\mathrm{P}_{3}$.

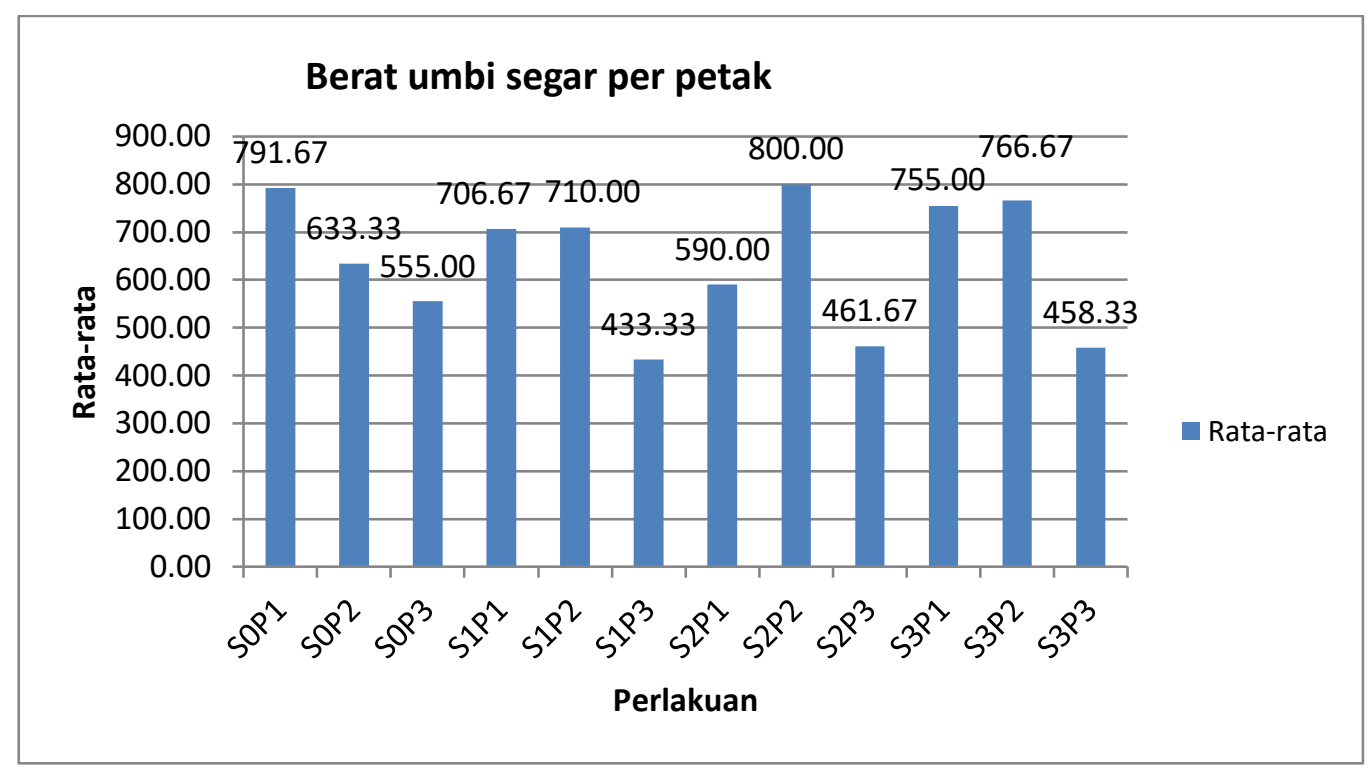

Jumini et al. (2010) menyatakan bahwa rendahnya nilai pertumbuhan dan hasi bawang merah pada pelakuan tanpa pemotongan umbi bibit diduga akibat lambatnya keluar mata tunas, sehingga pertumbuhan tunas dan pembentukan anakan terhambat dan mengakibatkan tanaman tidak tumbuh maksimal. (Samadi \& Cahyono., 2005) menyatakan bahwa pemotongan umbi bibit bertujuan untuk mempercepat pertumbuhan tunas dan meningkatkan jumlah anakan. 
Pemotongan umbi bibit tertinggi terhadap jumlah umbi segar per tanaman diperoleh pada perlakuan $\mathrm{P}_{1}$ (pemotongan umbi bibit $1 / 4$ bagian) dengan hasil 5,37, yang berbeda nyata terhadap perlakuan $\mathrm{P}_{2}$ dan $\mathrm{P}_{3}$.

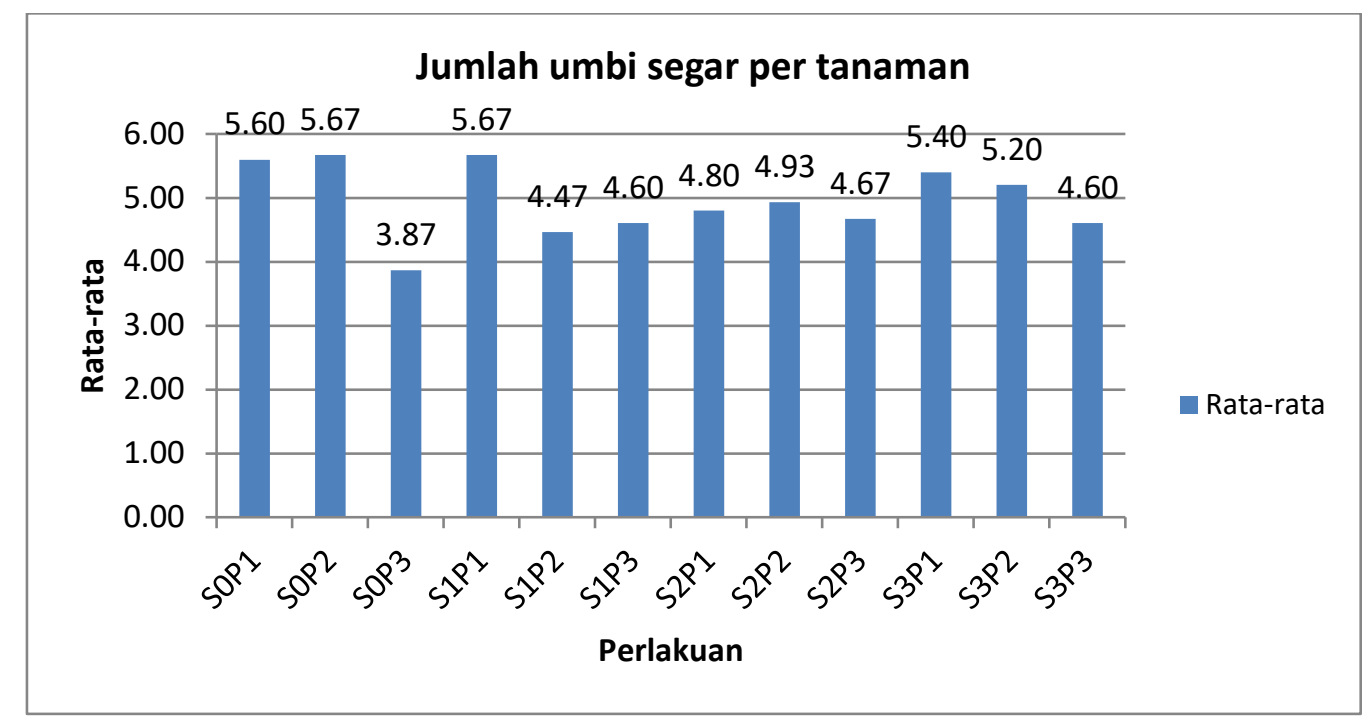

Rukmana (1995) menyatakan bahwa pemotongan umbi bibit mempunyai beberapa keuntungan, antara lain umbi bibit lebih cepat tumbuh dan berpengaruh terhadap banyaknya anakan. Hal ini ditunjukan pada perlakuan pemotongan umbi bibit 1/4 bagian memperoleh jumlah umbi lebih banyak dari perlakuan pemotongan umbi bibit lainnya. Hasil penelitian Putra et al. (2012) Pemotongan umbi bibit berpengaruh tidak nyata terhadap parameter jumlah daun, umur berbunga, panjang akar, jumlah anakan per sampel, jumlah umbi per sampel dan bobot segar umbi per sampel, namun ada kecenderungan pemotongan $1 / 2$ umbi bibit memberikan hasil tertinggi pada pertumbuhan tanaman (panjang akar, jumlah anakan per sampel, jumlah umbi per sampel). Hal ini diduga karena dengan pemotongan $1 / 2$ ujung umbi yang berakibat pada pengurangan cadangan makanan secara berlebihan, tanaman akan lebih aktif dalam mencari sumber makanan (unsur hara dan air) melalui pemanjangan akar dan penambahan jumlah keturunan melalui penambahan jumlah anakan (berhubungan dengan jumlah umbi) meskipun berakibat pada berkurangnya bobot segar umbi per tanaman maupun per luasan lahan (plot) sebagai akibat dari hasil fotosintat yang cenderung dialihkan ke penambahan panjang akar dan jumlah anakan sehingga pada perlakuan umbi dipotong $1 / 2$ ujung menunjukkan hasil lebih tinggi daripada umbi utuh dan umbi dipotong $1 / 4$ ujung umbi.

\section{Jumlah Umbi Segar Per Petak}

Konsentrasi bio slurry dan pemotongan umbi bibit berbeda tidak nyata menunjukan perbedaan antar perlakuan pada pengamatan jumlah umbi segar per petak, respon terbaik 
ditunjukan pada perlakuan $\mathrm{S}_{1} \mathrm{P}_{1}$ (konsentrasi bio slurry $50 \mathrm{ml} / \mathrm{l}$ dan pemotongan $1 / 4$ bagian) meskipun tidak memberikan pengaruh yang nyata terhadap jumlah umbi segar per petak.

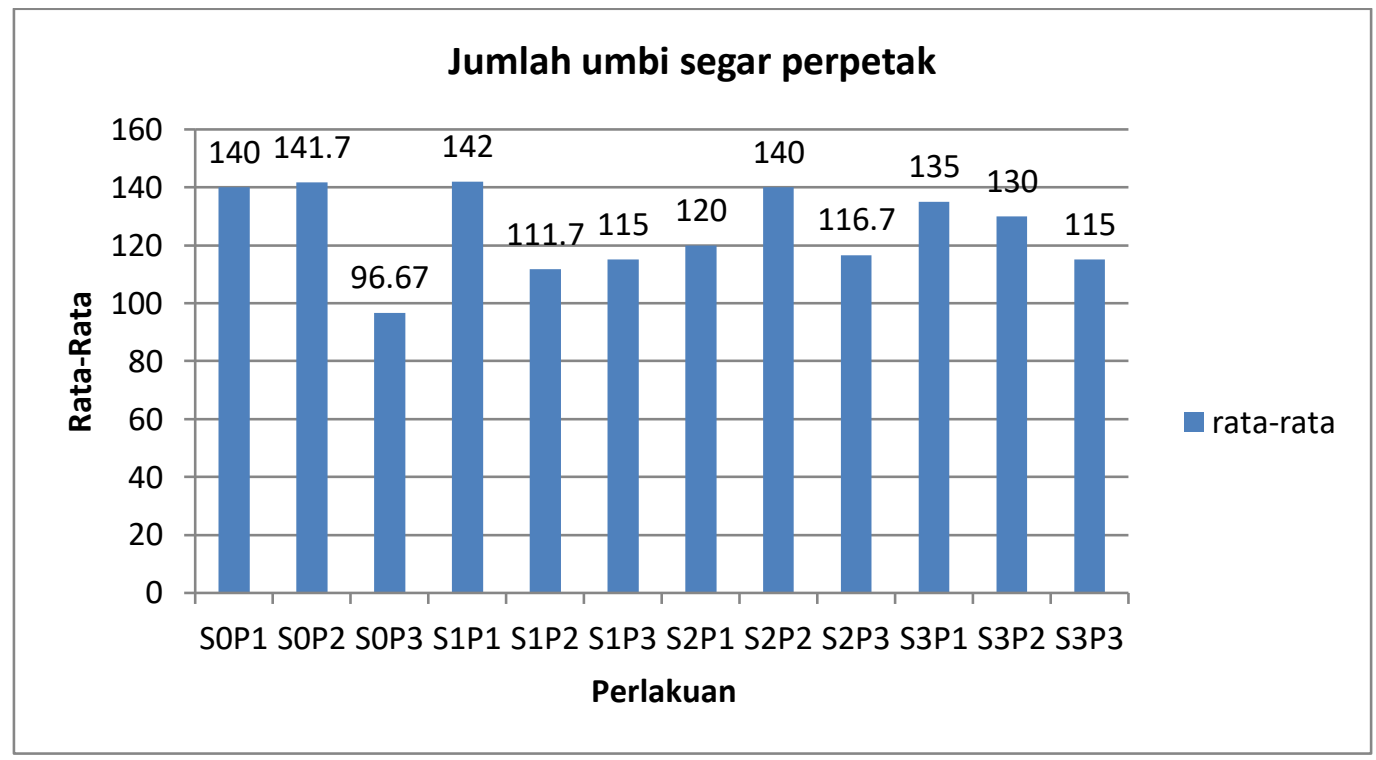

Menurut Azmi et al., 2011) diketahui perbedaan jumlah umbi bawang merah dipengaruhi oleh faktor genetik dari varietas bawang merah. Penelitian Salisburry \& Ross (1995) proses pemotongan umbi bibit akan mempermudah pertumbuhan tunas pada umbi bibit bawang merah karena tidak menghalangi pucuk tunas untuk tumbuh. Selain itu, pertumbuhan tanaman akan optimal jika unsur hara tang tersedia dalam jumlah dan bentuk yang sesuai dengan tanaman.

\section{Berat Brangkasan Segar}

Konsentrasi bio slurry (S), pemotongan umbi bibit $(\mathrm{P})$ serta interaksi konsentrasi bio slurry dan pemotongan umbi bibit $(\mathrm{SxP})$ tidak berpengaruh nyata terhadap berat berangkasan segar, tidak berpengaruh nyata terhadap berat brangkasan segar.

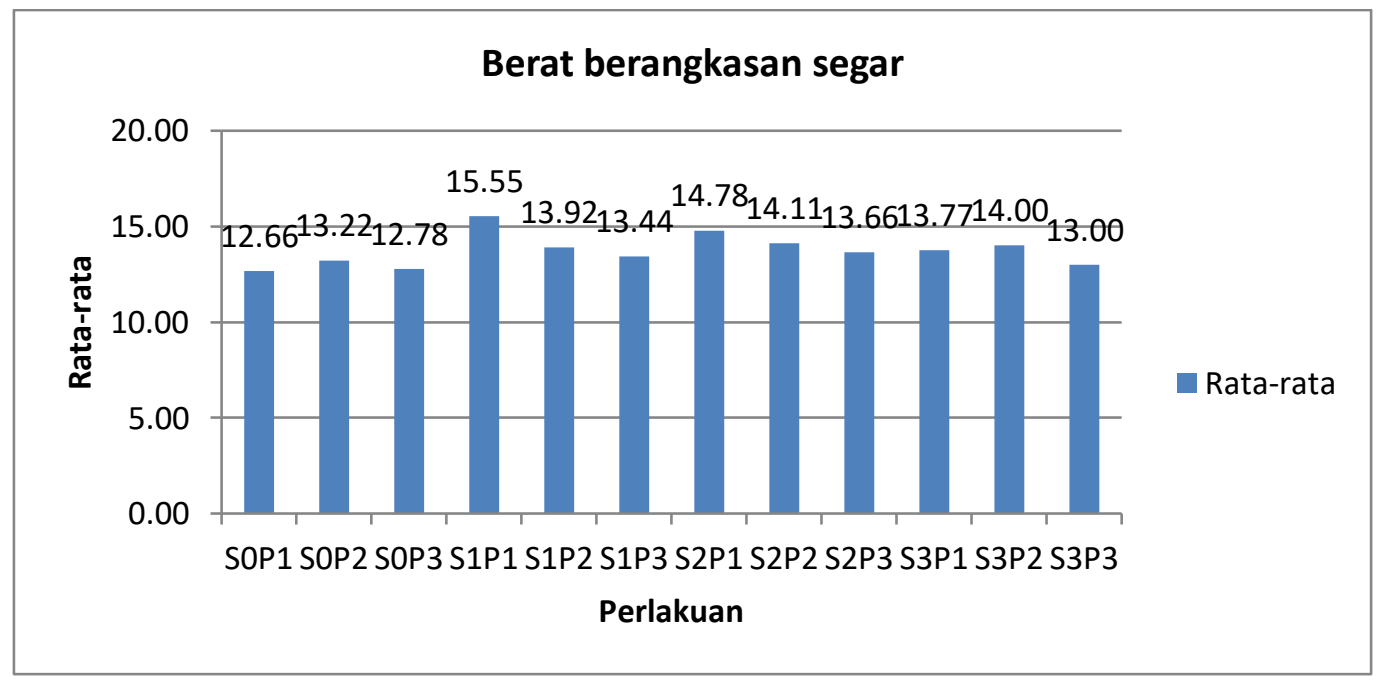

Konsentrasi bio slurry tidak memberikan hasil yang tidak berbeda nyata pada setiap perlakuan, namun hasil terbaik ditunjukan pada perlakuan $\mathrm{S}_{1} \mathrm{P}_{1}$ (konsentrasi slurry $50 \mathrm{ml} / \mathrm{l}$ dan 
pemotongan umbi bibit 1/4 bagian) dengan hasil 15,55 g. Menurut penelitian Mufairoh et al. (2018)dalam konsentrasi bio slurry memiliki manfaat untuk meningkatkan daya menahan air sehingga kelembaban tanah masih terjaga. Samadi \& Cahyono. (2005) menyatakan bahwa pemotongan umbi bibit bertujuan untuk mempercepat pertumbuhan tunas dan meningkatkan jumlah anakan.

\section{KESIMPULAN}

Hasil penelitian untuk peningkatan pertumbuhan dan hasil bawang merah (allium ascalonicum, $L$ ) dengan aplikasi perbedaan konsentrasi bio slurry dan pemotongan umbi bibit dapat disimpulkan sebagai berikut :

1. Konsentrasi bio slurry berpengaruh tidak nyata pada semua pengamatan yang diamati. Konsentrasi bio slurry terbaik bagi pertumbuhan dan hasil tanaman bawang merah adalah $S_{2}$ (konsentrasi bio slurry $100 \mathrm{ml} / \mathrm{l}$ ) yang berbeda nyata dengan $S_{1}$ dan $S_{3}$.

2. Pemotongan umbi bibit berpengaruh nyata pada pengamatan berat umbi per tanaman,berat umbi per petak dan jumlah umbi pertanaman. Pemotongan umbi bibit terbaik bagi pertumbuhan dan hasil tanaman bawang merah adalah $\mathrm{P}_{2}$ (pemotongan umbi bibit $1 / 3$ bagian) yang berbeda nyata dengan pemotongan $\mathrm{P}_{1}$ (pemotongan umbi bibit $1 / 4$ bagian) dan $\mathrm{P}_{3}$ (pemotongan umbi bibit 1/2 bagian).

3. Interaksi perlakuan antara konsentrasi bio slurry dan pemotongan umbi bibit terbaik bagi pertumbuhan dan hasil tanaman bawang merah diperoleh pada berat umbi per petak adalah $\mathrm{S}_{2} \mathrm{P}_{2}$ (konsentrasi bio slurry $100 \mathrm{ml} / \mathrm{l}$ dan pemotongan umbi bibit 1/3 bagian). Sedangkan untuk pengamatan lainnya menunjukan berbeda tidak nyata.

\section{DAFTAR PUSTAKA}

Anonim. (2007). Pedoman Bertanam Bawang. Kanisius, Yogyakarta.

Azmi, C., Hidayat, I. M., \& Wiguna, G. (2011). Pengaruh Varietas dan Ukuran Umbi terhadap Produktivitas Bawang Merah. Jurnal Hortikultura, 21(3), 206-213.

Hadisuwito, S. (2007). Membuat Pupuk Kompos Cair Agromedia. Gramedia, Jakarta.

Irfan, M. (2013). Respon Bawang Merah (Allium ascalonicum L.) Terhadap Zat Pengatur Tumbuh dan Unsur Hara. Jurnal Agroteknologi., 3(2), 35-40.

Jumini, Sufyati, Y., \& Fajri, N. (2010). Pengaruh Pemotongan Umbi Bibit dan Jenis Pupul Organik terhadap Pertumbuhan dan Hasil Bawang Merah. Jurnal Floratek., 5, 164-171.

Laude, S., \& Hadid, A. (2007). Respon Tanaman Bawang Merah Terhadap Pemberian Pupuk Cair Organik Lengkap. Jurnal Agrisains, 8(3), 140-146. 
Mufairoh, L., Laili, S., \& Rahayu, T. (2018). Pengaruh Pemberian Hasil Samping Pembuatan Biogas Sebagai Pupuk Organik Cair terhadap Pertumbuhan Bawang Merah (Allium cepa L.). EJ.SAINS ALAMI (Known Nature), 1(1).

Purnama, E. (2014). Pengaruh Pemotongan Umbi Bibit dan Dosis Kompos Azolla sp. Terhadap Pertumbuhan dan Hasil Tanaman Bawang Merah (Allium ascalonicum L.). Unpublished Thesis. Universitas Sultan Ageng Tirtayasa (UNTIRTA).

Puspa, R. D. (2019). Pengaruh Takaran Kompos Kotoran Sapi dan jenis Mulsa Terhadap pertumbuhan dan Produksi Bawah Merah (Allium ascalonicum L). Unpublished Dissertasion. Universitas Muhammadiyah Palembang.

Putra, R. Y., Haryati, H., \& Mawarni, L. (2012). Respons Pertumbuhan Dan Hasil Bawang Sabrang (Eleutherine Americana Merr.) Pada Beberapa Jarak Tanam Dan Berbagai Tingkat Pemotongan Umbi Bibit. Jurnal Agroekoteknologi Universitas Sumatera Utara, $1(1)$.

Salisburry, F. B., \& Ross, C. W. (1995). Fisiologi Tumbuhan. (Jilid I. E). ITB. Bandung.

Samadi, B., \& Cahyono., B. (2005). Bawang Merah. Kanisius. Yogyakarta.

Suriani, N. (2012). Bawang Bawa Untung. Budidaya Bawang Merah dan Bawang Putih. Cahaya Atma pustaka. Yogyakarta.

Wibowo, S. (2005). Budidaya Bawang Putih Bawang Merah dan Bawang Bombay. Penebar Swadaya, Jakarta.

Yunus, M. (1991). Pengelolaan Limbah Peternakan. Animal Husbandry Project. Unpublished Thesis. Universitas Brawijaya. 